\title{
КОНСТИТУЦИОННЫЕ НОРМЫ, ОПРЕДЕЛЯЮЩИЕ СТАТУС РЕБЕНКА В РОССИЙСКОЙ ФЕДЕРАЦИИ. ПРАВО РЕБЕНКА НА СЕМЬЮ
}

\section{CONSTITUTIONAL NORMS DEFINING \\ THE STATUS OF A CHILD IN THE RUSSIAN \\ FEDERATION. THE CHILD'S RIGHT \\ TO A FAMILY}

M. Pryanikova

Summary. This article will deal with the study of the specifics of the implementation of constitutional guarantees and the means of the national legal system of Russia in relation to ensuring the subjective rights of minors in the sphere of the family legislation of the Russian Federation.

Keywords: the legal system of the Russian Federation, civil legal capacity, constitutional status, subjective rights, legislation.

\author{
Пряникова Мария Анатольевна \\ Аспирант, Московский городской педагогический \\ университет \\ Pryanikovamaria@mail.ru
}

Аннотация. В данной статье пойдет речь 06 изучении особенностей реализации конституционных гарантий и средств национальной правовой системы России в отношении обеспечения субъективных прав несовершеннолетних, в сфере семейного законодательства Российской Федерации.

Ключевые слова: правовая система Российской Федерации, гражданская правоспособность, конституционный статус, субъективные права, законодательство.

- с одной стороны, инфантицид как отвлечение от ребенка, детоубийство в формах отказа от здоровых детей, миллионов абортов, социального сиротства, детской беспризорности.

Социальная ситуация развития ребенка на пороге третьего тысячелетия нуждается в научном осознании и прогнозировании перспектив развития детства и требует концентрации усилий всех ответственных за ее нормализацию: профессиональных воспитателей и родителей, исследователей детства и практиков различных ориентации, особенно представителей юридической науки.

Каждый человек имеет право жить и воспитываться в семье, насколько это возможно. Предоставленное ребенку это право означает, что ребенок должен проживать со своими родителями. Ведь для всестороннего и гармоничного ребенка содержится важный для правового статуса детей принцип, согласно с которым для полного и гармоничного развития личности ребенку необходимо расти в семейном окружении, в атмосфере счастья, любви и понимания.

В СК РФ также определено, что каждое лицо имеет право жить и воспитываться в семье, насколько это возможно. Предоставленное ребенку это право означает, что ребенок должен проживать со своими родителями или его законными представителями - лица, которые их заменяют. Достигнув 14-летнего возраста, несовершен- 
нолетние с разрешения своих законных представителей могут выбирать место своего проживания.

Главной и самой необходимой функцией семьи и воспитание будущего гражданина, члена общества, человека, именно от семьи зависит, каким гражданином, членом общества станет ребенок. Семья всегда была и остается основным источником материальной и эмоциональной поддержки ее членов, необходимой для развития каждого из них, средством сохранения и передачи культурных ценностей от поколения к поколению, восстановление населения и воспитания полноценных членов общества. Итак, семья зависит от общества, в котором функционирует, так же, как и общество зависит от семьи. Это двустороннее воздействие может быть как прогрессивным, так и разрушительным. Характеризуя семью с юридической точки зрения, ученый по гражданскому праву - Кокорина М.С. обращала внимание, что семья считается союзом лиц, связанных браком, и лиц, которые происходят от них. При этом автор отмечала, что семья е основным звеном государственного механизма, пользуясь при этом определенной автономией [11].

По мнению А.М. Нечаевой, семья является специфической формой социальной жизнедеятельности людей, обусловленная экономическим строем общества, основанная на браке или родства, включая всю совокупность отношений, складывающихся на базе совместной разносторонней деятельности ее членов, в которой реализуются не только потребности общества, но и потребности каждого отдельного индивида [9].

Зато Кордуба С.Б. предлагает следующее юридическое определение семьи: семья - это юридическая связь между физическими лицами, основанный на браке, отношениях родства, усыновлении и других основаниях, предусмотренных в законе, который проявляется в наделении их на началах равенства взаимными личными неимущественными и имущественными семейными правами и обязанностями, совместной жизни, общности интересов и взаимной юридической ответственности [5].

Проблема осуществления и защиты права ребенка жить и воспитываться в семье всегда была актуальной. Несмотря на то, что право жить и воспитываться в семье е одним из основных личных неимущественных прав ребенка. Суть данного права сводится к предоставлению и обеспечение ребенку возможности жить и воспитываться в семье. При этом в данном случае речь идет о кровной семье, которую образуют родители. Семейное воспитание и наилучшей формой воспитания ребенка, которую знает человечество, ведь никакие общественные формы воспитания не могут сравниться с семейными.
Поэтому современное правовое положение ребенка в российском обществе требует новых подходов к решению проблем, связанных с осуществлением права ребенка на проживание и воспитание в семье.

Каждый ребенок имеет право жить и воспитываться в семье, которая е лучшим средой для формирования личности ребенка. Этот принцип е главным в формировании государством курса социальной и правовой политики. Право на проживание в семье принадлежит новорожденному ребенку и может быть реализовано в первую очередь благодаря тому, что родители или другие лица заберут ее из роддома [6].

Специфика субъекта права жить и воспитываться в семье заключается в его физической беспомощности и невозможности понимать значение окружающих его обстоятельств в раннем детстве и полной зависимости от родителей или лиц, которые их заменяют. В таком правоотношении превалируют действия обязанного лица (родителей или лиц, их заменяющих).

Общие пределы конституционных гарантий, провозглашающих особый статус ребенка в России, обозначены в статье 17 Конституции РФ, согласно которой конституционные границы правового положения ребенка (как и любого человека и гражданина) определяются: общепризнанными принципами, нормами международного права и российской Конституцией, моментом рождения человека, совокупностью прав и свобод других лиц, нарушение которых допускается согласно части 3 статьи 55 Конституции РФ только в исключительных случаях, установленных федеральным законом.

Конституционные нормы, определяющие статус ребенка в России, гарантируют государственную защиту установленных в Основном законе детских прав, которые изначально характеризуются правоспособностью человека, возникающей в момент его рождения и прекращающейся смертью. Конституционные нормы, определяющие статус ребенка в России, начинают действовать с появлением его на свет и способствуют регламентации правовой охраны неродившихся граждан на случай их рождения. Совокупность конституционных прав и свобод других лиц, которые относятся к несовершеннолетним, представляют собой широкий спектр конституционных гарантий обеспечения прав и законных интересов человека, поскольку на сегодняшний день Конституция РФ фактически не содержит норм, определяющих правовой статус хотя бы одного специального субъекта права. Вместе с тем, в главе 2 Конституции РФ назван полный перечень прав и обязанностей, распространяемых либо на «каждого» либо на «гражданина РФ». Представляется, что гражданин Российской Федерации, которому не исполнилось 18 лет, может рассчи- 
тывать на распространение данных норм и на себя. Причем любое исключение из данного правила должно быть зафиксировано в законодательном порядке [1]. Значит, в России на несовершеннолетнего по общему правилу распространяется весь конституционный комплекс прав и обязанностей.

Но хочется отметить один из важнейших аспектов конституционных прав - право ребенка на неприкосновенность семейной жизни.

В статье 12 Всеобщей декларации прав человека установлено, что «Никто не может подвергаться произвольному вмешательству в его личная и семейная жизнь, безосновательного посягательства на неприкосновенность его жилья, тайну его корреспонденции или на его честь и репутацию. Каждый человек имеет право на защиту законом от такого вмешательства или таких посягательств» [13, Art. 12]. А статья 5 Декларации предусматривает, что «Никто не должен подвергаться унижающего его достоинство, обращение и наказание» [13, Art. 5].

Принцип 2 Декларации прав ребенка гласит, что ребенок должен развиваться в условиях свободы и достоинства [3].

Статья 8 Конвенции о защите прав человека и основополагающих свобод определяет, что каждый имеет право на уважение своей частной и семейной жизни, его жилища и корреспонденции; органы государственной власти не могут вмешиваться в осуществление этого права, за исключением случаев, когда вмешательство осуществляется согласно законом и необходимо в демократическом обществе в интересах национальной и общественной безопасности или экономического благосостояния страны, для предотвращения беспорядков или преступлений, для защиты здоровья или морали или для защиты прав и свобод других лиц [14, Art. 8].

В статье 17(1) Международного пакта о гражданских и политические права установлено, что « никто не должен подвергаться произвольного или незаконного вмешательства в его личную и семейную жизнь, произвольных или незаконных посягательств на неприкосновенность его жилища или тайну его корреспонденции или незаконных посягательств на его честь и репутацию» [12, Art. 17(1)].

Статья 16 Конвенции о правах ребенка предусматривает, что «ни одна ребенок не может быть объектом произвольного или незаконного вмешательство в осуществление ее права на личную и семейную жизнь, неприкосновенность жилья, тайну корреспонденции или незаконного посягательства в ее честь и достоинство.
Ребенок имеет право на защиту закона от такого вмешательства или посягательства» [2, Art. 17(1)].

Общие пределы конституционных гарантий, провозглашающих особый статус ребенка в России, обозначены в статье 17 Конституции РФ, согласно которой конституционные границы правового положения ребенка (как и любого человека и гражданина) определяются: общепризнанными принципами, нормами международного права и российской Конституцией, моментом рождения человека, совокупностью прав и свобод других лиц, нарушение которых допускается согласно части 3 статьи 55 Конституции РФ только в исключительных случаях, установленных федеральным законом.

Конституционные нормы, определяющие статус ребенка в России, гарантируют государственную защиту установленных в Основном законе детских прав, которые изначально характеризуются правоспособностью человека, возникающей в момент его рождения и прекращающейся смертью. Конституционные нормы, определяющие статус ребенка в России, начинают действовать с появлением его на свет и способствуют регламентации правовой охраны неродившихся граждан на случай их рождения. Совокупность конституционных прав и свобод других лиц, которые относятся к несовершеннолетним, представляют собой широкий спектр конституционных гарантий обеспечения прав и законных интересов человека, поскольку «на сегодняшний день Конституция РФ фактически не содержит норм, определяющих правовой статус хотя бы одного специального субъекта права. Вместе с тем, в главе 2 Конституции РФ назван полный перечень прав и обязанностей, распространяемых либо на «каждого» либо на «гражданина РФ». Представляется, что гражданин Российской Федерации, которому не исполнилось 18 лет, может рассчитывать на распространение данных норм и на себя. Причем любое исключение из данного правила должно быть зафиксировано в законодательном порядке» [4]. Значит, в России на несовершеннолетнего по общему правилу распространяется весь конституционный комплекс прав и обязанностей [5].

Социальный опыт, к которому привлекается ребенок с первых дней жизни, аккумулируется и проявляется в социальной культуре. Следовательно, возникает важный вопрос о том, как происходит становление образа мира вообще и социума в частности в сознании ребенка на ранних этапах социализации. Картина мира, его познание, мировоззрение - один из самых исследуемых и в то же время все еще не исследованных научных терминов.

Процесс познания мира изучается различными науками: философией - как взаимодействие объекта 
и субъекта, результатом которого является новое знание о мире; психологией - как система пространств, отражающих смысловые отношения субъекта с миром; педагогикой - как совокупность представлений об окружающем мире, и место в нем ребенка, начиная с дошкольного возраста; юриспруденцией - нормативно-правовое регулирование всех взаимодействий ребенка с окружающим его миром.

Проблема детской правовой защищенности во все времена оказывается также актуальной юридической проблемой, она рассматривается в различных аспектах, однако все равно остается недостаточно исследованной. Современная юридическая наука определяет детскую правовую защитную систему как особую систему мировоззрения социума, вмещающее в себя совокупность представлений, смысловых отношений относительно основных сторон взаимодействия ребенка с миром и проявляется через различные виды нормативно-правовой ответственности.

Право ребенка на семью обусловлено рядом основных правомочий несовершеннолетнего: правом знать своих родителей, правом ребенка на воспитание своими родителями, правом на заботу родителей и совместное с ними проживание, правом на обеспечение его интересов, правом всестороннего развития и уважения его человеческого достоинства, правом на особую заботу при утрате родительского попечения.

Никто не вправе скрывать от ребенка информацию о том, кто фактически является его родителями (за исключением случаев соблюдения тайны усыновления) [6; 7].

Каждый ребенок имеет право на воспитание своими родителями. Под воспитанием детей подразумевается «планомерное воздействие на личность, обеспечение правильного, то есть отвечающего собственным и общественным интересам развития нравственности, культуры, образования, знаний и навыков несовершеннолетнего, необходимых для социально полезной деятельности и общения» [8].

Понимание того, что наилучшей средой для полноценного развития ребенка считается семья, сформировано на основе данных различных гуманитарных наук [4]. На основе этого сформулирован принцип приоритетности семейного воспитания перед всеми другими формами, закрепленный в СК РФ. Свое развитие данный принцип получил в ряде субъективных прав несовершеннолетних, закрепленные в главах СК РФ, а именно: право проживать вместе с родителями (родными или приемными), право на заботу со стороны родителей, право на общение с родителями и другими родственниками, право, насколько это возможно, знать своих родителей и др.
Содержание права физического лица на семью составляют:

1. право на создание семьи;

2. право на свободный выбор формы организации своей семейной жизни и способа реализации права на семью;

3. право на выбор лиц, которые будут образовывать семью;

4. право на проживание в семье;

5. право на уважение к своей семейной жизни;

6. право на поддержание связей с членами своей семьи и родственниками независимо от того, где человек находится;

7. запрещение развода с семьей вопреки воле лица, кроме случаев, установленных законом.

Из представленного содержания права на семью следует, что право жить и воспитываться в семье является частью более общего права на семью. Однако не все составляющие этого права входят в правовой статус ребенка. Так, малолетний ребенок не может создавать семью, не может выбирать форму организации своей семейной жизни и способы реализации права на семью, не может избирать лиц, с которыми создавать семью.

В современной правовой литературе относительно содержания права ребенка жить и воспитываться в семье существуют разные точки зрения. Некоторые авторы считают, что данное личное неимущественное право является сложным по своему содержанию. По их мнению, право ребенка проживать с родителями, право ребенка знать своих родителей, право на заботу и уважение его достоинства е структурными элементами права жить и воспитываться в семье. Согласно другой точки зрения, перечисленные выше права следует рассматривать как самостоятельные и равнозначные [10].

Право ребенка жить и воспитываться в семье включает в себя определенную совокупность прав, которые и составляют содержание данного права. В частности Митрякова Е.С. считает, что «право ребенка жить и воспитываться в семье предполагает следующие виды личных неимущественных прав ребенка: право жить в семье; право воспитываться в семье; право знать своих родителей (насколько это возможно); право на их заботу; право на совместное с ними проживание, за исключением случаев, когда это противоречит его интересам; право на воспитание своими родителями; право на обеспечение его интересов; право на всестороннее развитие; право на уважение ее человеческого достоинства» [7].

В процессе анализа субъективного права ребенка на воспитание современная литература, не всегда акцентирует внимание на том, что в семейном праве РФ е 
два вида указанного права. Одно из них принадлежит детям другое - их родителям. Поскольку воспитание детей е наиболее важной и основной функцией семьи, то права и обязанности по воспитанию детей, в первую очередь, принадлежат родителям.

Некоторые ученые рассматривают право на воспитание как единственное право, из которого вытекают правомочия, входящие в его содержания, обучения детей и общения с ними [10].

Право на воспитание можно охарактеризовать как совокупность мер, применяемых родителями во время общения с детьми с целью передачи им своих знаний, жизненного опыта, убеждений, обеспечение нормального психического и физического развития детей и защиты их интересов.

С такой позицией нельзя согласиться в полной мере с учетом того, что право нельзя характеризовать как совокупность мер. Согласно нашему мнению, можно уточнить, если определять право родителей на воспитание своих детей как предусмотренную законодательством возможное поведение родителей в отношении своих детей, направленную на передачу им своих знаний, жизненного опыта, убеждений, обеспечение нормального психического и физического развития детей и защиты их интересов.

Существует мнение, согласно которому право ребенка на воспитание существует как в отношении родителей и лиц, их заменяющих, так и общества в целом. Обязанность воспитывать детей возлагается прежде всего на родителей, а при отсутствии родителей - на усыновителей, опекунов, попечителей. Воспитание - это система интеллектуального и эмоционального воздействия на ребенка со стороны родителей, дошкольных заведений, школы, профессионально-технических училищ, техникумов. При этом праву ребенка на воспитание соответствует обязанность родителей воспитывать своих детей. Вместе с тем, обязанность родителей по воспитанию детей е одновременно и их правом.

Кабакова О.В. обращает внимание на то, что в законодательстве содержание права на воспитание не раскрывается, поскольку четко очертить его границы невозможно - это обусловлено тесным переплетением включаемых правомочий с другими родительскими правами (например, с правом на совместное проживание или общение с родителями) [8].

В контексте этой темы необходимо обратить внимание на обязанности, корреспондирующих данному праву. Так, праву ребенка жить и воспитываться в семье корреспондирует обязанность родителей или лиц, которые их заменяют, не только обеспечить воспитание ребенка, но и создать необходимые условия для жизни и ее нормального развития. Кроме того, на государство в лице уполномоченных законом органов возлагается обязанность обеспечить надлежащие условия для реализации данного права и контролировать выполнение родителями или лицами, которые их заменяют, возложенных на них законом семейных обязанностей.

Обеспечение гражданских прав и интересов необходимы для дальнейшей жизни ребенка и его становления социально активным гражданином своей страны, поскольку основным ресурсом любого государства, безусловно, является его народ, потенциал которого закладывается в детстве и в подростковом возрасте.

\section{ЛИТЕРАТУРА}

1. Конституция Российской Федерации» (принята всенародным голосованием 12.12.1993) (с учетом поправок, внесенных Законами РФ о поправках к Конституции РФ от 30.12.2008 N6-ФК3, от 30.12.2008 N7-ФК3, от 05.02.2014 N2-ФK3, 0т 21.07.2014 N11-ФK3). URL: http://www.consultant.ru/document/cons_ doc_LAW_28399.

2. Convention on the Rights of the Child. Adopted and opened for signature, ratification and accession by General Assembly resolution 44/25 of 20 November $1[89$, entered into force on 2 September 1990, in accordance with article 49. URL: https://www.ohchr.org/en/professionalinterest/pages/crc.aspx.

3. Declaration of the rights of the child. Proclaimed by UN General Assembly Resolution 1386 (XIV) of 20 November 1959. URL: https://www.unicef.org/malaysia/1959Declaration-of-the-Rights-of-the-Child.pdf (дата обращения: 01.03.2020).

4. Борисова Н. Е. Правовое положение несовершеннолетних в Российской Федерации (монография): Издание третье.— М.: изд-во «Союз», $2007 .-$ с. 205.

5. Кордуба С. Б. Конституционная обязанность родителей заботиться о детях в Российской Федерации: Дис. канд. юрид. наук. Саратов, 2011. С. 6.

6. Малеина М. Н. Человек и медицина в современном праве. М., 1995.

7. Митрякова Е.С. Правовое регулирование суррогатного материнства в России: Дис. канд. юрид. наук. Тюмень, 2006.

8. Кабакова О. В. Конституционные обязанности граждан в России: эволюция правовой регламентации и практика реализации. Теоретический и историко-правовой анализ: Дис. канд. юрид. наук. Краснодар, 2006. С. 187.

9. Нечаева А. М. Семейное право: Учебник. 4-е изд., перераб. и доп. М.: Юрайт; ИД «Юрайт», 2011. С. 95.

10. Косова 0. Ю. Семья и право ребенка на образование // Труды Института государства и права Российской академии наук. 2008. ⒉ С. 26.

11. Кокорина М. С. Семейно-правовые основы воспитания детей в современной России: Дис. канд. юрид. наук. М., 2006. С. 48. 
12. International Covenant on Civil and Political Rights. Adopted and opened for signature, ratification and accession by General Assembly resolution $2200 \mathrm{~A}$ (XXI) of 16 December 1966, entry into force 23 March 1976. URL: https://www.ohchr.org/en/professionalinterest/pages/ccpr.aspx (дата обращения: 03.03.2020).

13. Universal Declaration of Human Rights. Proclaimed by the UN General Assembly Resolution 217 A (III) in Paris on 10 December 1948. URL: http://www.un.org/en/ udhrbook/pdf/udhr_booklet_en_web.pdf (дата обращения: 03.03.2020).

14. Convention for the Protection of Human Rights and Fundamental Freedoms (ETS No 005). Rome, 04/11/1950. Entry into force: 03/09/1953. URL: https://www.coe. int/en/web/conventions/fulllist/-/conventions/treaty/005 (дата обращения: 03.03.2020).

П Пряникова Мария Анатольевна ( Pryanikovamaria@mail.ru).

Журнал «Современная наука: актуальные проблемы теории и практики»

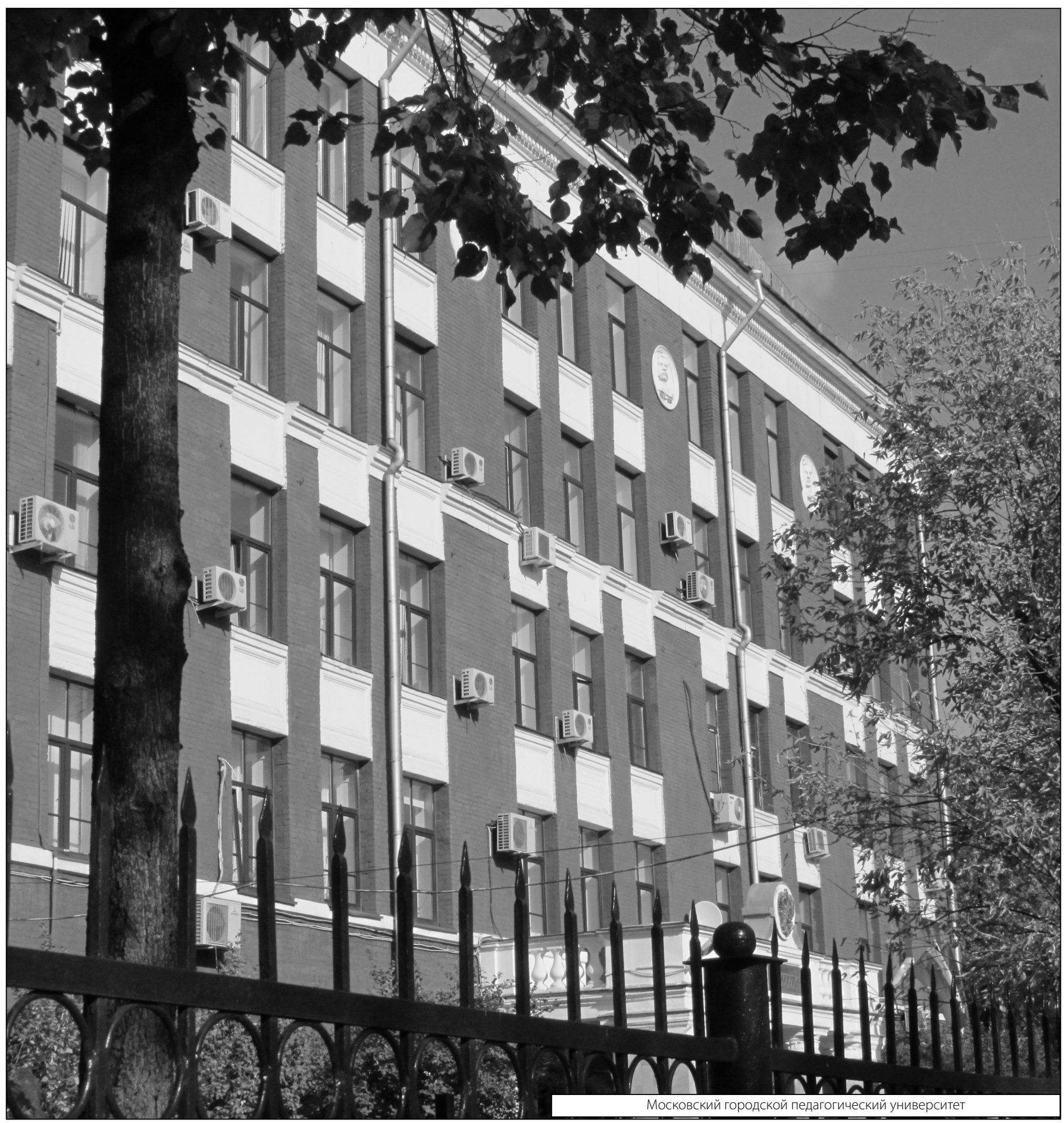

